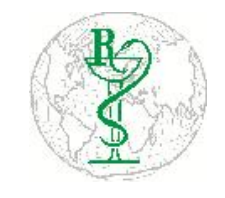

INDO GLOBAL JOURNAL OF

PHARMACEUTICAL SCIENCES

ISSN 2249- 1023

\title{
An Effective Method for Isolation of Pure Swertiamarin from Enicostemma littorale Blume
}

\author{
Satyender Kumar ${ }^{* 1}$, Vinod Jairaj ${ }^{2}$ \\ ${ }^{1}$ Department of Natural Products, National Institute of Pharmaceutical Education and Research (NIPER)-Ahmedabad Opposite Air-Force Station, \\ Palaj, Gandhinagar, Gujarat 382354, India \\ ${ }^{2}$ Department of Pharmaceutical Analysis, National Institute of Pharmaceutical Education and Research (NIPER)-Ahmedabad Opposite Air-Force \\ Station, Palaj, Gandhinagar, Gujarat 382354, India
}

\begin{abstract}
Address for
Correspondance Satyender Kumar, sjinagal@gmail.c om

Received:

28.11.2017

Accepted:

11.02.2018

ABSTRACT: Swertiamarin, a secoiridoid glycoside is one of the major components and an active lead isolated from a perennial herb Enicostemma littorale (EL) Blume. Swertiamarin has been reported for its number of pharmacological activities namely, hepatoprotective, antiedematogenic/anti-inflammatory, free radical scavenging activity, antispastic activity, dyslipidemia, hypolipidemic effect and anti-hyperlipidemic effect. Thus, swertiamarin has the potential to be a successful drug candidate in the future in the treatment of various diseases. Isolation and characterization of the swertiamarin following a published procedure didn't yield the reported purity. Considering the therapeutic importance of swertiamarin, there is a need for the development of an effective method for the compound in good yield and purity. This method involves column chromatography of a methanolic extract of dried whole plant powder material of Enicostemma littorale Blume for the isolation in pure form. Swertiamarin, as colorless crystals with a yield of $7.3 \%, 97.5 \%$ purity by HPLCPDA analysis was isolated and characterized by MS, IR and ${ }^{1} \mathrm{H}-\mathrm{NMR}$. Comparison was done with reported literature. The percentage yield and purity of isolated swertiamarin was improved by this method. (C) 2018 iGlobal Research and Publishing Foundation. All rights reserved.
\end{abstract}

Keywords

Swertiamarin; Enicostemma littorale; HPLC; Purity; Quality.

\section{INTRODUCTION}

Accordingly, International Diabetes Federation (IDF), 387 million patients were affected by diabetes mellitus in 2014 and the numbers will be increased up to 592 million people worldwide, by $2030^{1}$. This means that diabetes is a major health problem affecting millions of people across the world ${ }^{2}$. Today, among metabolic disorders, diabetes mellitus can be considered a serious and expensive public health problem Worldwide $^{3-5}$. The causes of diabetes can be varied including insulin deficiency due to pancreatic $\beta$-cells destruction and abnormality in insulin sensitivity which leads to insulin resistance. This impairs signal transduction in insulin signaling, which will eventually result in hyperglycemia ${ }^{6}$.
Chronic hyperglycemia can lead to cardiovascular disease, retinopathy, neuropathy, nephropathy, and diabetic foot disease $^{7,8}$. Despite considerable progress in the treatment of diabetes by available treatments, diabetes and its secondary complications continue to be a major medical problem. The search for newer drugs continues because the existing synthetic drugs have several limitations and also unable to alleviate the pleiotropic effects of diabetes mellitus. Natural sources have always been an exemplary source of drugs and many of the currently available drugs have been derived directly or indirectly from them ${ }^{9,10}$. Morphine, vinblastine, vincristine, quinine, artemisinin, etoposide, teniposide, paclitaxel and camptothecin are some examples of pharmaceuticals derived from natural compounds ${ }^{6}$. 
Indo Global Journal of Pharmaceutical Sciences, 2018; 8(1): 1-8

Swertiamarin is present in many plants like Anthocleista procera Lept. Ex Bureau, Blackstonia perfoliata L. Hudon, Centaurium erythraea Rafn., Enicostemma littorale, Gentiana macrophylla Pall, Gentiana manshurica Kitag, Gentiana scabra Bunge, Swertia chiraytiya Roxb ex. Flem Kurst., Swertia davidi Franch, Swertia patens Burk, Swertia mileensis, Swertia pseudochinesis H. Hara. ${ }^{11}$. It has very low toxicity ${ }^{12}$ and Vishwakarma et al. suggested that swertiamarin was one of the major components of Enicostemma littorale (Fig. 1).

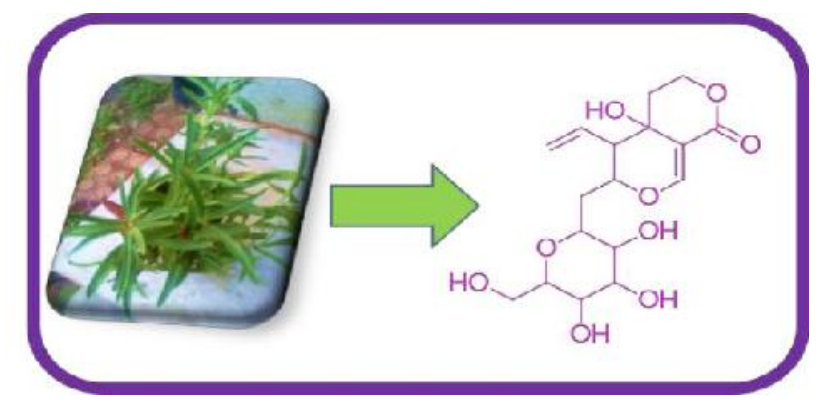

Figure 1 Structure of swertiamarin from Enicostemma littorale

Swertiamarin is a secoiridoid glycoside and recently it has been reported for its number of pharmacological effects namely, antidiabetic ${ }^{13,14}$, antiarrithritic activity ${ }^{15}$, hepatoprotective, antiedematogenic/anti-inflammatory, free radical scavenging activity ${ }^{16}$, a CNS depressant effect and anticholinergic activity $^{17-19}$, anticholinergic ${ }^{18}$, antibacterial activity ${ }^{20}$, neurotrophic activity ${ }^{21}$. The separation, isolation and purification of bioactive compounds with purity, good quality as well as in quantity from a from a crude extract or fractions of an extract is a long and expensive process ${ }^{22}$, because of the target compound(s) presence in a matrix of dozens of other constituents ${ }^{23}$. Natural product chemistry usually begins from the separation and isolation of single pure compound from such many structurally related ingredients ${ }^{22,24}$. Most separation procedures, however, require diverse chromatographic methods ${ }^{23}$. Column chromatography has found its place in many laboratories for the preparative purpose. The advantage of column chromatography is mainly due to: simple packing procedure, low operating pressure, and inexpensive instrumentation ${ }^{25}$. However, the basic prerequisite for successful separations in column chromatography is the choice of the proper adsorbent and mobile phase. Adsorbent particle size affects how the solvent flows through the column ${ }^{26}$. The previously reported methods of swertiamarin isolation were not efficient at quantitative as well as qualitative levels. Therefore, we have developed a new method for the isolation of pure swertiamarin by column chromatography, which is rapid, economical method for the isolation of swertiamarin in high yields and purity by column chromatography.

\section{MATERIALS AND METHODS}

\section{Plant materials}

\section{Collection and identification of the plant}

The whole plant of Enicostemma littorale was collected from Dharampur, Valsad district in November 2012. The material was authenticated by a taxonomist and identity was confirmed by referring Flora of Gujarat ${ }^{27}$. A voucher specimen NIPERA/NP/1112/05 was submitted at NIPER- Ahmedabad, India. Plant material was shade-dried, powdered and stored in air tight container for further use.

\section{Equipment's/Apparatus/Materials}

Rotary evaporator (R-210) was used for solvent evaporation and pre-coated TLC plates (silica gel $60 \mathrm{~F}_{254}$ (E. Merck), panisaldehyde reagent (Spectrochem), UV-cabinet (CAMAG), silica gel (230-400\#) (Merck, Germany), melting point apparatus (VEEGO-VMP-PM), twin trough TLC chamber (10x10), HPTLC (CAMAG) were used during swertiamarin isolation.

\section{Extraction and isolation of swertiamarin}

Powdered plant material $(50 \mathrm{~g})$ was loaded in a $250 \mathrm{ml}$ Erlenmeyer flask and fatty material removed by washing with chloroform $(5 \times 200 \mathrm{ml})$ until the extraction solvent became colorless. TLC analysis of the system (chloroform: methanol, 8.5: $1.5 \mathrm{v} / \mathrm{v})$ indicated complete removal of the fats. The material was extracted with methanol $(4 \mathrm{x} 500 \mathrm{ml})$ by cold maceration. TLC analysis (chloroform: methanol (8.5: $1.5 \mathrm{v} / \mathrm{v}$ ) indicated complete extraction of swertiamarin. The methanolic extract was filtered through Whatman filter paper $(10)$ and concentrated to $50 \mathrm{ml}$. The methanolic extract obtained was treated with cold diethyl ether to obtain $17 \mathrm{~g}$ of a precipitate. The precipitate was loaded on a chromatography column with slurry of 230-400 mesh silica gel and eluting solvent chloroform, ensuring that no air bubbles form. Gradient elution, starting with chloroform and then with chloroform /methanol (0-5\%), followed by further increment of methanol in the decimal scale (5.1-5.9\%). The isolation procedure was monitored by TLC for swertiamarin (chloroform: methanol (8.5: $1.5 \mathrm{v} / \mathrm{v})$. Visualization was done at $254 \mathrm{~nm}$ followed by derivatization with p-anisaldehyde for presence of other impurities. Fractions containing swertiamarin were pooled and concentrated to dryness to obtain $3.6 \mathrm{~g}$ of the material. The isolated swertiamarin was stored at $-20^{\circ} \mathrm{C}$ until required for further study. The identification of swertiamarin was done by using HPTLC (CAMAG) and purity of standard and isolated swertiamarin at $1 \mu \mathrm{g} / \mathrm{ml}$ and $5 \mu \mathrm{g} / \mathrm{ml}$ was determined by 
Indo Global Journal of Pharmaceutical Sciences, 2018; 8(1): 1-8

HPLC-PDA system (SHIMADZU LC-2010; PDA detector $(200-400 \mathrm{~nm})$. The characterization of isolated swertiamarin was done by using different spectral techniques such as: Infrared(IR) spectra were recorded on Fourier-transform Infrared (FTIR) spectrophotometer (Shimadzu), atmospheric pressure ionization with ion spray mass spectra of molecular ions were obtained on a Perkin-Elmer, API 165 mass spectrometer (LC/MS), and 1H-Nuclear magnetic resonance (1H-NMR) spectra was recorded in MeOD using Fouriertransform (FT)-NMR spectrometer (Bruker Advance II (500 $\mathrm{MHz}$ ), Switzerland).

\section{General experimental procedures}

\section{Preparation of $p$-Anisaldehyde reagent}

$85 \mathrm{ml}$ of methanol was taken in $500 \mathrm{ml}$ glass measuring cylinder and $10 \mathrm{ml}$ glacial acetic acid was added and thoroughly mixed with a glass stirring rod. After that $5 \mathrm{ml}$ sulphuric acid $\left(\mathrm{H}_{2} \mathrm{SO}_{4}\right)$ was added in to mixture followed by addition of $0.5 \mathrm{ml} \mathrm{p}$-Anisaldehyde to the mixture and reagent was ready to be prepared fresh before use.

\section{Identification and comparison of $U V$ absorption spectrum of} isolated swertiamarin with standard swertiamarin

HPTLC analysis was performed on pre-coated plates of silica gel 60 F254 (E Merck, 139 Kiesel gel 60 F254, 0.2 mm) and samples were applied on the plates using CAMAG 140 LINOMAT 5 Automatic TLC spotter (Switzerland). The swertiamarin sample along with the standard was developed (chloroform: methanol 8.5: $1.5 \mathrm{v} / \mathrm{v}$ ), and UV spectra recorded on a CAMAG TLC Scanner 3 with CAMAG 1.3.0 WinCATS software. The melting point of standard and isolated swertiamarin was checked by using a melting point apparatus (VEEGO-VMP-PM) and UV absorption spectrum of the isolated swertiamarin was taken at start, middle, and end positions of the band by HPTLC.

\section{Purity profiling of isolated swertiamarin by HPLC}

Purity of isolated swertiamarin and standard swertiamarin was determined by using HPLC-PDA (High performance thin layer chromatography with photodiode detector) in solvent gradient system Ammonium acetate/Acetonitrile (85: 15) at 1 $\mu \mathrm{g} / \mathrm{ml}$ and $5 \mu \mathrm{g} / \mathrm{ml}$ concentration.

\section{RESULTS AND DISCUSSION}

Swertiamarin (Fig. 2) of purity $97.5 \%$ was isolated with a yield of $7.3 \%$ using the current developed method. The melting point of isolated swertiamarin was observed at 113$114{ }^{\circ} \mathrm{C} . \mathrm{R}_{\mathrm{f}}(0.30)$ of the isolated swertiamarin is same as same as that of standard reference swertiamarin. In addition to swertiamarin, an additional compound was isolated, which had an $R_{f}$ of 0.28 as shown in (Fig. 5). Overlay UV absorption spectra of isolated swertiamarin with additional compound was recorded (Fig. 9) as well as overlay UV spectrum of standard and isolated unknown compound was recorded and max of isolated swertiamarin and swertiamarin standard was come at $242 \mathrm{~nm}$ as shown in (Fig. 10). The purity of standard and isolated swertiamarin by HPLC was 97.7 and 97.2, respectively at $1 \mu \mathrm{g} / \mathrm{ml}$ and $5 \mu \mathrm{g} / \mathrm{ml}$ concentration as shown in (Fig. 11-14).

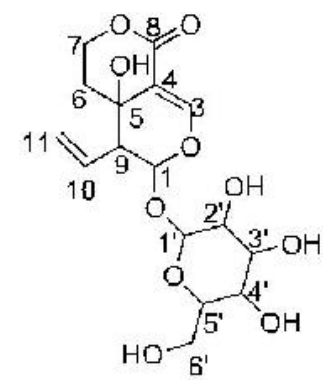

Figure 2 Structure of Swertiamarin

The isolated sample of swertiamarin was identified and characterized from its spectral data (MS, IR, and ${ }^{1} \mathrm{H}-\mathrm{NMR}$ ), which matched well with that of the standard swertiamarin. The molecular ion peak of isolated swertiamarin MS $\mathrm{m} / \mathrm{z}$ was $375.2\left(\mathrm{M}^{+}\right)$(Fig. 6) whereas reference standard swertiamarin $\mathrm{MS} \mathrm{m} / \mathrm{z}$ was $375.1\left(\mathrm{M}^{+}\right)$.FTIR spectra of isolated swertiamarin and standard swertiamarin showed several intense peaks in the wave number region between $4000-400 \mathrm{~cm}^{-1}$ such as $\mathrm{O}-\mathrm{H}$ (stretch.) $3347 \mathrm{~cm}^{-1}, \mathrm{C}-\mathrm{H}$ (stretch.) $2923 \mathrm{~cm}^{-1}, \mathrm{C}=\mathrm{O}$ (stretch.) $1696 \mathrm{~cm}^{-1}, \mathrm{C}=\mathrm{C}$ (stretch.) $1617 \mathrm{~cm}^{-1}, \mathrm{C}-\mathrm{O}-\mathrm{C}$ (stretch.) $1408 \mathrm{~cm}^{-}$ ${ }^{1}, \mathrm{C}=\mathrm{CH}_{2}$ (stretch.) $846 \mathrm{~cm}^{-1}$ (Fig. 7). Isolated swertiamarin showed the following ${ }^{1} \mathrm{H}-\mathrm{NMR}$ signals in (MeOD): chemical shift values $(\delta): 1.28$ (ddd, H6- $\alpha$ ), 1.28 (ddd, H6- $\beta$ ), 2.83 (dd, H-9), 3.81 (dd, H-7ß), 4.26 (dd, H-7 $\alpha$ ), 5.63 (dd, H-1), 7.54 (s, H-3), Gluocose:3.56 (m, H-2",3",4",5"), 3.81 (dd, H-7 $\alpha$ ), 4.44 (dd, H-7ß), 4.66 (ddd, H-1") (Fig. 8).

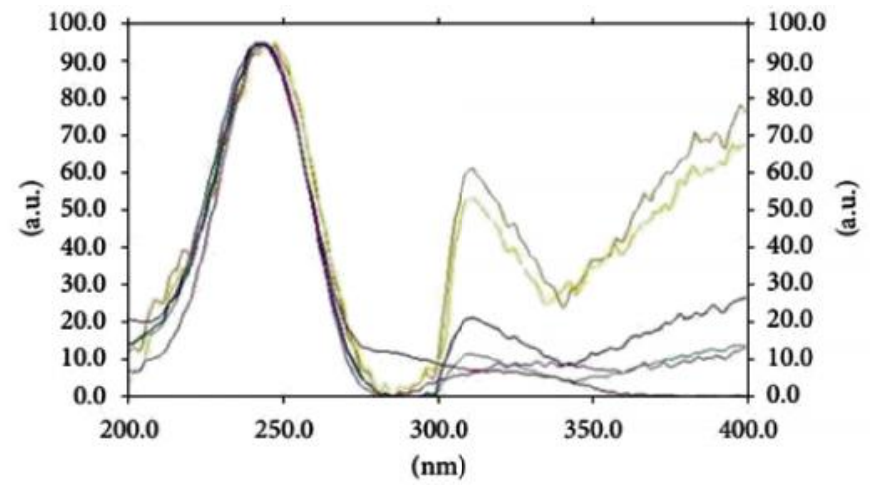

Figure 3 Overlay of ultraviolet absorption spectrum of swertiamarin isolated in lab and reference standard as reported by Patel et al., 31 . 
Indo Global Journal of Pharmaceutical Sciences, 2018; 8(1): 1-8

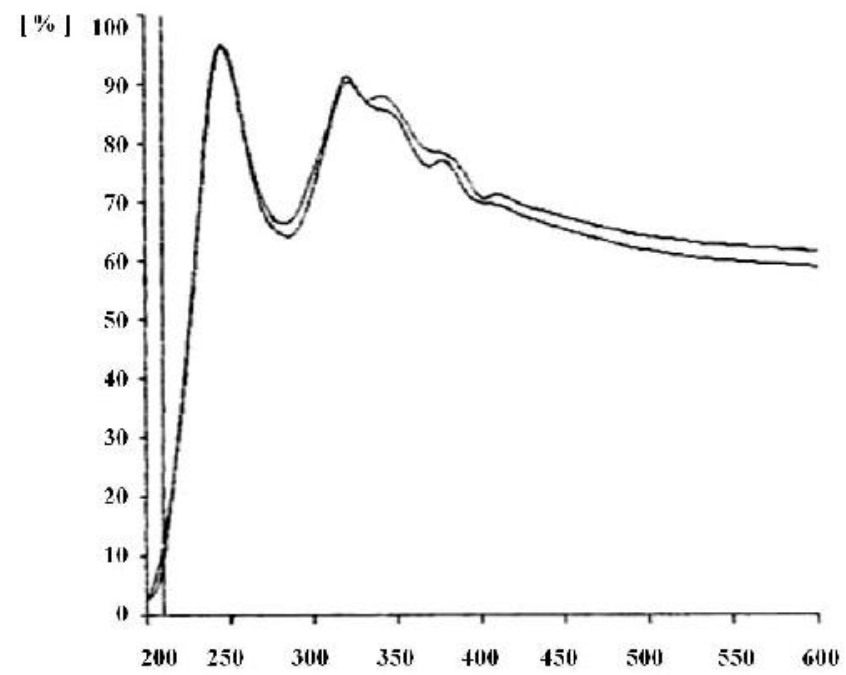

Figure 4 Overlay of ultraviolet absorption spectrum of swertiamarin isolated in lab and reference standard as reported by Vishwakarma et al. ${ }^{13}$.

Various reported methods for the isolation of swertiamarin reported different yields: $5 \% \mathrm{w} / \mathrm{w}$ by Vishwakarma et al. ${ }^{13}$ and $0.4 \% \mathrm{w} / \mathrm{w}$ by Jaishree et al. ${ }^{28}$, using column chromatography over silica gel (60-120\#), $0.66 \%$ w/w by Magora et al. ${ }^{29}$ using sephadex LH-20 and $2 \%$ w/w by Rana ${ }^{30}$ using Centrifugal Partition Chromatography from Enicostemma axillare. Different melting points were reported for isolated swertiamarin, such as Vishwakarma et al. ${ }^{13}$ in 2004 reported that melting point of isolated swertiamarin was shrinking from $70{ }^{\circ} \mathrm{C}$ and Patel et al. ${ }^{31}$ in 2013 was reported that the melting point of swertiamarin was $196-197^{\circ} \mathrm{C}$.

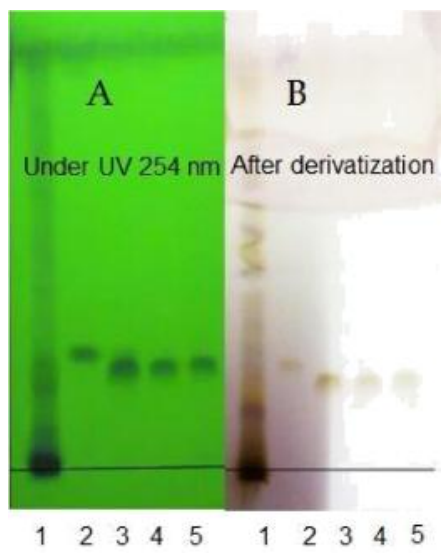

Figure 5 TLC Fingerprint profile of (1): Defatted methanolic extract; (2): Isolated Unknown Compound; (3): Mixture of unknown compound with swertiamarin; (4): Isolated swertiamarin; (5): Standard swertiamarin by current method in the TLC mobile phase (chloroform: methanol 8.5:1.5). A) TLC visualization under UV $254 \mathrm{~nm}$ and B) after derivatization.

Hence, reported purity of isolated swertiamarin varied. But, a melting point can be used to tentatively identify pure compounds in their solid state. The presence of even a small amount of impurity lowers compound's melting point by a few degrees and broaden the melting point temperature range ${ }^{32}$. By using our method, a sharp melting point of isolated swertiamarin was observed at $113-114{ }^{\circ} \mathrm{C}$ and compared with the data mentioned $113-114{ }^{\circ} \mathrm{C}$ in Merck Index, $2103^{33}$ which matched that mentioned $\left(113-114{ }^{\circ} \mathrm{C}\right)$ in Merck Index, $2103^{33}$ which is the physical characteristic of pure compound.

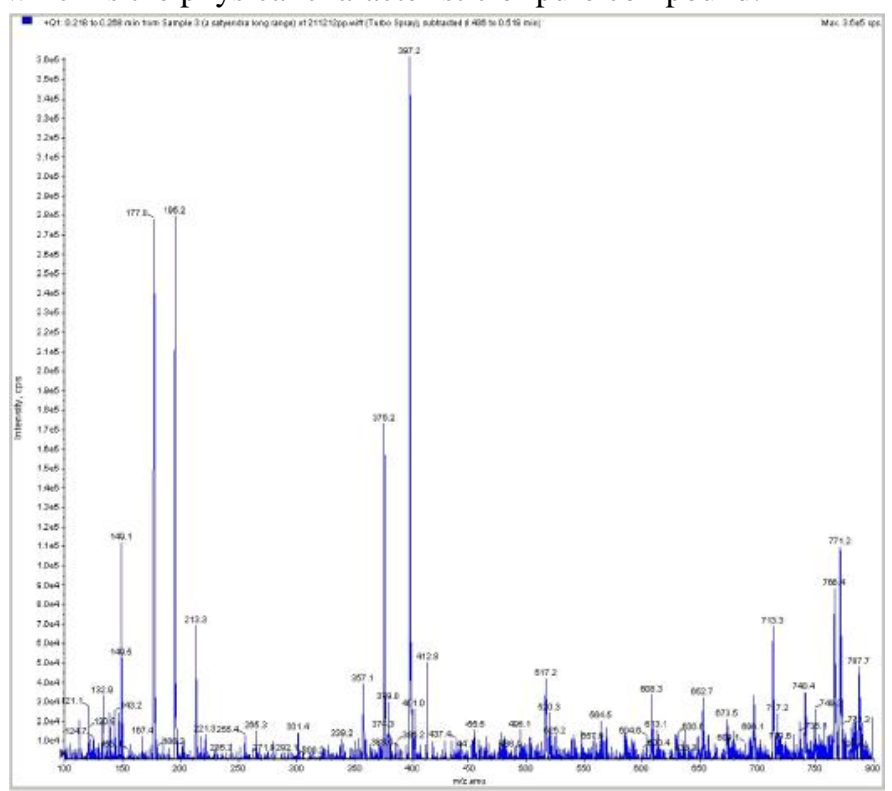

Figure 6 Mass spectrum of isolated swertiamarin at 375 m/z.

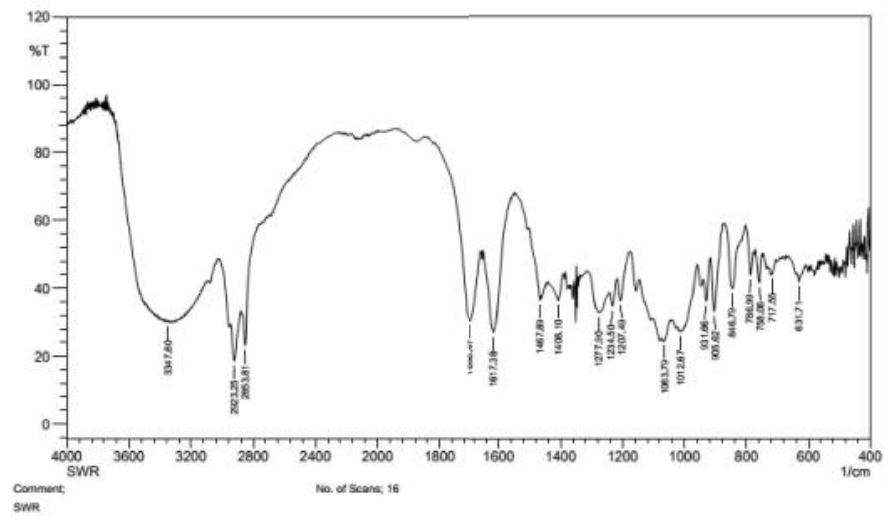

Figure 7 FT-IR spectra of isolated swertiamarin showed several intense peaks in the wave number region between $4000-400 \mathrm{~cm}^{-}$ ${ }^{1}$ suchas O-H (stretch.) $3347 \mathrm{~cm}^{-1}, \mathrm{C}-\mathrm{H}$ (stretch.) $2923 \mathrm{~cm}^{-1}, \mathrm{C}=\mathrm{O}$ (stretch.) $1696 \mathrm{~cm}^{-1}, \mathrm{C}=\mathrm{C}$ (stretch.) $1617 \mathrm{~cm}^{-1}, \mathrm{C}-\mathrm{O}-\mathrm{C}$ (stretch.) $1408 \mathrm{~cm}^{-1}, \mathrm{C}=\mathrm{CH} 2$ (stretch.) $846 \mathrm{~cm}^{-1}$.

In a typical chromatogram, co-eluting impurities give rise to peaks that are imperfectly separated from the peak of the main substance. If their concentrations are high, this shows up as shoulder patterns in the chromatogram. By virtue of Beer's law, one can presume that a spectro-chromatogram corresponding to the combined absorption of the main substance and a co-eluting impurity consists of the sum of two single bilinear structures. In terms of data analysis, there are therefore two significant principal components plus noise (hetero-scedastic) ${ }^{34}$. The shoulder pattern was observed in 
Indo Global Journal of Pharmaceutical Sciences, 2018; 8(1): 1-8

reports by Patel et al., (Fig. 3) and Vishwakarma et al., (Fig. 4) for in UV absorption spectrum for isolated swertiamarin.

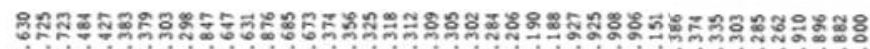

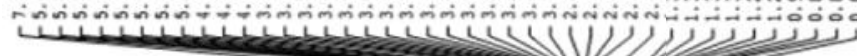

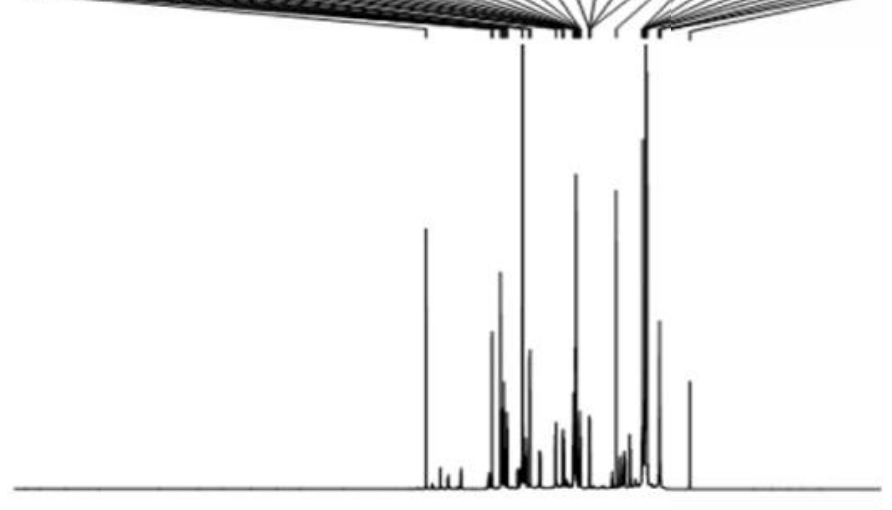

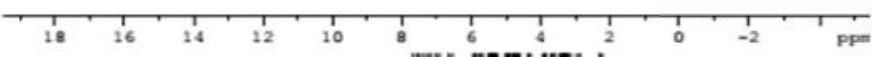

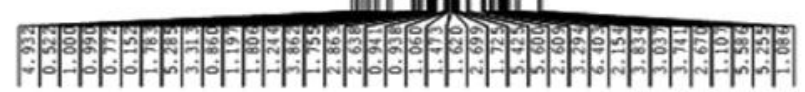

Figure 8 Isolated swertiamarin showed the following 1H-NMR signals in (MeOD): chemical shift values ( $\delta): 1.28$ (ddd, H6- $\alpha$ ),

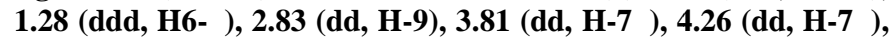
5.63 (dd, H-1), 7.54 (s, H-3), Glucose: 3.56 (m, H-2",3”,4”,5”),

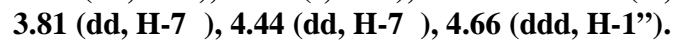

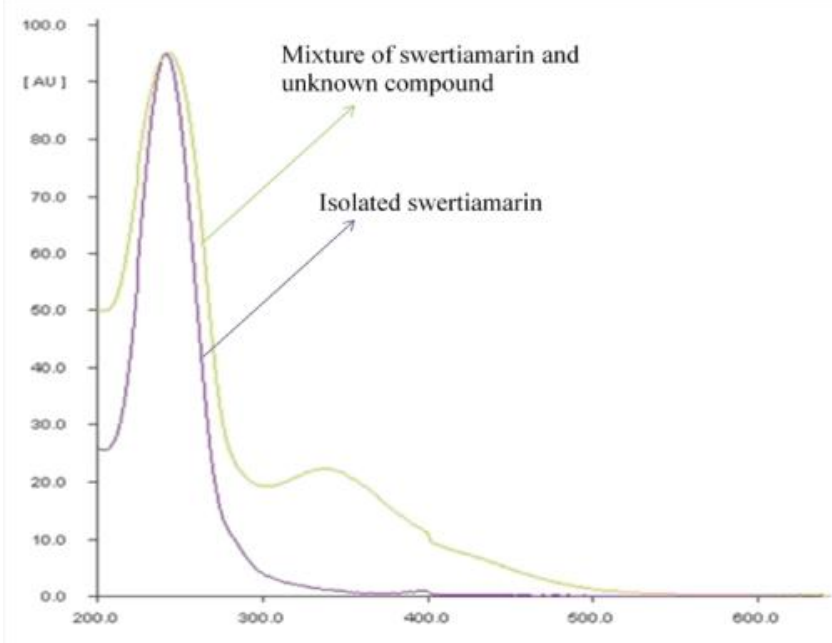

Figure 9 Overlay of ultraviolet absorption spectrum of swertiamarin and swertiamarin along with impurity (In-House)

The signature of UV absorption spectrum of swertiamarin with additional compound which was observed during isolation of swertiamarin (Fig. 9) was same as the UV spectrum which was observed during isolation of swertiamarin by Vishwakarma et al. in 2004. The molecular ion peak of swertiamarin at $\mathrm{m} / \mathrm{z}$ of 374 was reported by Patel et $\mathrm{al}^{31}$ in 2013. However, the molecular ion peak of swertiamarin in positive ion mode should come at $375 \mathrm{~m} / \mathrm{z}$ in Mass Spectrum as shown in (Fig. 6) was observed for isolated swertiamarin by currently developed method and the data comparison with Merck Index ${ }^{33}$; IR spectrum of isolated swertiamarin as shown in (Fig. 7) and ${ }^{1}$ H-NMR spectrum as shown in the (Fig. 8) was compared with reported literature ${ }^{35}$ by ICMR(Indian Council of Medical Research), Delhi. Peak purity determination with a diode-array detector is a powerful tool to check peak purities. By comparing spectra from the upslope, apex and down slope impurities with less than $0.5 \%$ can be identified ${ }^{36}$. The purity of standard and isolated swertiamarin by HPLC-PDA, 97.7\% and $97.2 \%$ was observed by currently developed method.

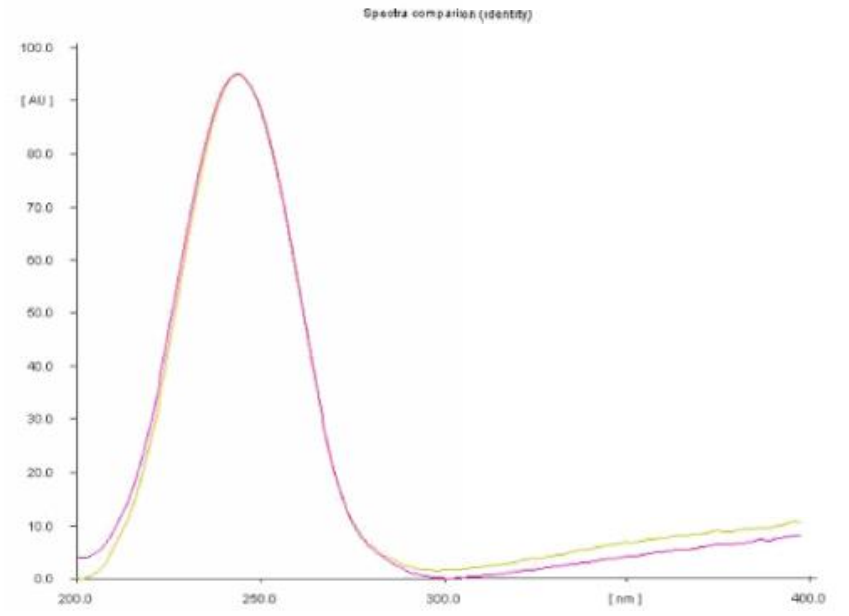

Figure 10 Identity comparison by overlay of ultraviolet absorption spectrum of reference standard (Pink color) and isolated swertiamarin (Yellow color) (INHOUSE)

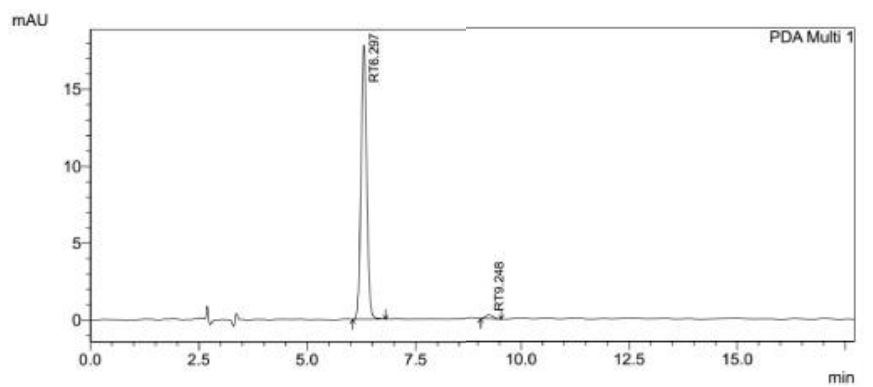

Figure 11 HPLC chromatogram of standard swertiamarin at $1 \mathrm{~g} / \mathrm{ml}$ concentration

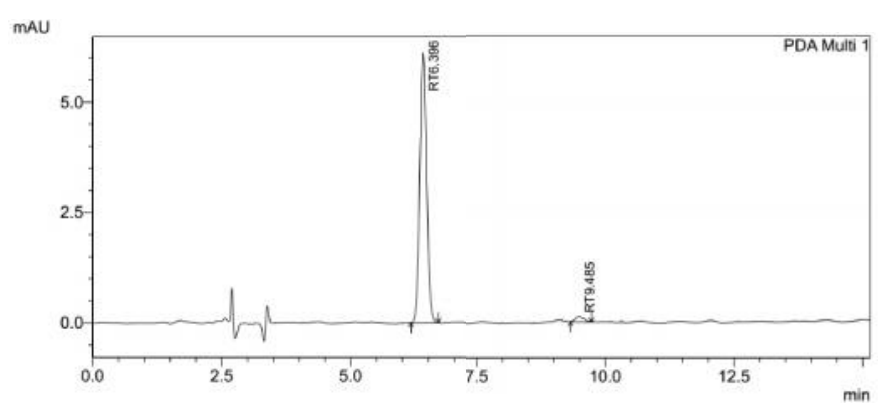

Figure 12 HPLC chromatogram of isolated swertiamarin at 1 $\mu \mathrm{g} / \mathrm{ml}$ concentration

Different research papers have reported different melting points and spectra. The purity is reflected in various spectral data in current developed method. The unknown compound is 
Indo Global Journal of Pharmaceutical Sciences, 2018; 8(1): 1-8

separated from swertiamarin by using this method. The comparison of reported data and lab developed data as shown in Table 1. The main advantage of our process is that it completely omits the use of highly tedious, time taking and expensive chromatographic purification process used in prior art processes and gives more yield than all the earlier reported processes.

mAU

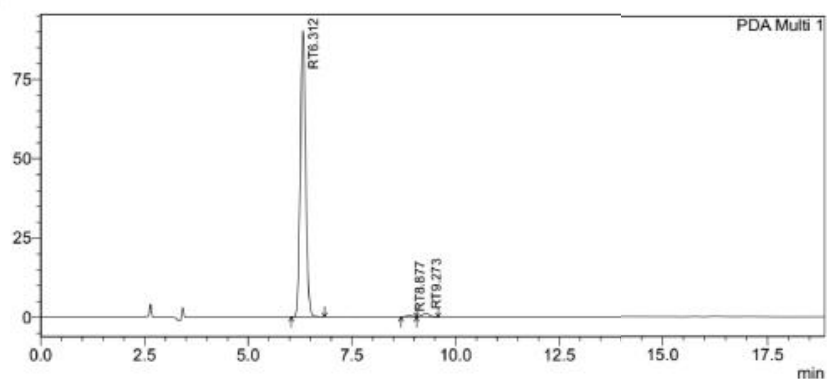

Figure 13 HPLC chromatogram of standard swertiamarin at 5 $\mathrm{g} / \mathrm{ml}$ concentration

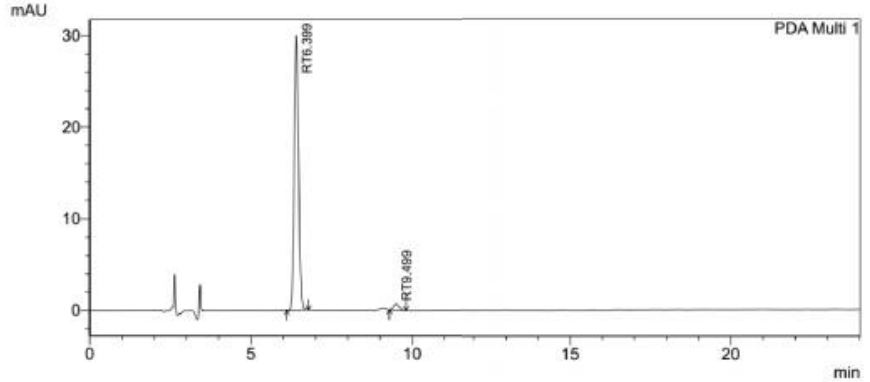

Figure 14 HPLC chromatogram of isolated swertiamarin at 5 g/ml concentration

\section{CONCLUSION}

The study demonstrates the utility of this developed method to isolate pure swertiamarin form Enicostemma littorale in a fast and effective manner. The lab-generated data was compared with reported data and found that this method is the best method for the isolation of pure swertiamarin in quality as well as quantity.

\begin{tabular}{|c|c|c|}
\hline & Reported methods & Developed method \\
\hline Silica used & $\begin{array}{l}\text { Silica gel (60 mesh } \\
\text { size) }\end{array}$ & $\begin{array}{l}\text { Silica gel (230-400 mesh } \\
\text { size) }\end{array}$ \\
\hline Separation & Not good & Very good \\
\hline $\begin{array}{l}\text { Solvents required for } \\
\text { column } \\
\text { chromatography }\end{array}$ & $\begin{array}{l}\text { Petroleum ether, ethyl } \\
\text { acetate, methanol, } \\
\text { diethyl } \\
\text { ether, chloroform }\end{array}$ & $\begin{array}{l}\text { Chloroform, methanol, } \\
\text { diethyl ether }\end{array}$ \\
\hline Melting point & $\begin{array}{l}\text { Sharp melting point was } \\
\text { not observed. } \\
\text { Decomposition was } \\
\text { observed at } \\
70^{\circ} \mathrm{C}(\text { Vishwakarma et } \\
\text { al., } \\
2004 \text { ) and } 196-197^{\circ} \mathrm{C} \\
\text { (Patel et al., 2013) was } \\
\text { reported }\end{array}$ & $\begin{array}{l}\text { Sharp melting point } 113 \text { - } \\
114{ }^{\circ} \mathrm{C} \text { was observed }\end{array}$ \\
\hline Re-crystallization & Required & Not required \\
\hline $\begin{array}{l}\text { Purity of isolated } \\
\text { swertiamarin }\end{array}$ & $\begin{array}{l}\text { Purity was not } \\
\text { determined } \\
\text { by HPLC }\end{array}$ & $\begin{array}{l}\text { Purity was determined by } \\
\text { HPLC }(97.2 \%)\end{array}$ \\
\hline UV spectrum & $240-245 \mathrm{~nm}$ & Sharp peak at $242 \mathrm{~nm}$ \\
\hline Isolation of impurity & Not done & Done \\
\hline
\end{tabular}

Table 1 Comparison between reported method and lab developed method 


\section{Indo Global Journal of Pharmaceutical Sciences, 2018; 8(1): 1-8}

More importantly, the developed method is efficient for extraction and isolation would aid in sufficient amount for carrying out experiments to explore swertiamarin biological activities. So using this method the pace for research on swertiamarin will be increased.

\section{ACKNOWLEDGEMENT}

This research was supported by Department of Pharmaceuticals (DoP, Ministry of Chemicals and Fertilizers, Govt. of India). We thank Rev. Dr. S. Ignacimuthu, S.J. Director, Entomology Research Institute Loyola College, Chennai, Tamil Nadu, India for providing swertiamarin standard.

\section{CONFLICT OF INTEREST}

We wish to confirm that this research supported by Department of Pharmaceuticals (DoP, Ministry of Chemicals and Fertilizers, Govt. of India) and NIPER-Ahmedabad. We wish to draw the attention of the Editor to the following facts which may be considered as potential conflicts of interest and to significant financial contributions to this work.

\section{REFERENCES}

1. Florencia Aguiree, Alex Brown, Nam Ho Cho, Gisela Dahlquist, Sheree Dodd, ... Trisha Dunning, Michael Hirst, Christopher Hwang, Dianna Magliano, Chris Patterson, Courtney Scott, Jonathon Shaw, Gyula Soltesz, Juliet Usher-Smith, David Whiting Florencia Aguir DW. IDF DIABETES ATLAS Sixth Edition.; 2013. http://www.idf.org/sites/default/files/EN_6E_Atlas_Full_0.pdf. Accessed May 12, 2015.

2. Patel A, Chalmers J, Poulter N. ADVANCE: action in diabetes and vascular disease. J Hum Hypertens. 2005;19 Suppl 1:S27-32. doi:10.1038/sj.jhh.1001890.

3. Narayan KMV, Gregg EW, Fagot-Campagna A, Engelgau MM, Vinicor F. Diabetes - A common, growing, serious, costly, and potentially preventable public health problem. Diabetes Res Clin Pract. 2000;50(SUPPL. 2). doi:10.1016/S0168-8227(00)00183-2.

4. Zatalia SR, Sanusi $H$. The role of antioxidants in the pathophysiology, complications, and management of diabetes mellitus. Acta Med Indones. 2013;45(2):141-147.

5. Galuppo M, Giacoppo S, Bramanti P, Mazzon E. Use of natural compounds in the management of diabetic peripheral neuropathy. Molecules. 2014;19(3):2877-2895. doi:10.3390/molecules 19032877.

6. Jung HS, Lim Y, Kim E-K. Therapeutic phytogenic compounds for obesity and diabetes. Int J Mol Sci. 2014;15(11):21505-21537. doi:10.3390/ijms151121505.

7. Schmitz Rudolf. JSTOR: Pharmacy in History, Vol. 27, No. 2 (1985), pp. 61-74. Pharmacy in History. http://www.jstor.org/discover/10.2307/41109546?uid=3738256\&uid $=2 \& u i d=4 \&$ sid $=21106570319583$. Published 1985. Accessed April 24,2015

8. Donaghuea KC, Chiarellib F, Trottab D, And JA, Dahl-Jorgensend $\mathrm{K}$. Microvascular and macrovascular complications associated with diabetes in children and adolescents. Pediatric Diabetes. https://www.ispad.org/sites/default/files/resources/files/ispad_guideli nes_2009_-_vascular_complications.pdf. Published 2009. Accessed April 24, 2015.

9. Wadkar KA, Magdum CS, Patil SS NN. Anti-diabetic potential and Indian medicinal plants | rajendra kshirsagar - Academia.edu. Journal of Herbal Medicine and Toxicology. http://www.academia.edu/3441533/Anti-

diabetic_potential_and_Indian_medicinal_plants. Published 2008 . Accessed April 24, 2015

10. Arumugam G, Manjula P, Paari N. A review: Anti diabetic medicinal plants used for diabetes mellitus. $J$ Acute Dis. 2013;2(3):196-200. doi:10.1016/S2221-6189(13)60126-2.

11. Singh A. Phytochemicals of Gentianaceae. A review of pharmacological properties. Int J Pharm Sci Technol. 2008;1(1):3336.

http://www.researchgate.net/publication/228628170_Phytochemicals _of_Gentianaceae._A_review_of_pharmacological_properties.

Accessed July 15, 2015.

12. Mandal. Naturally Occurring Iridoids With Pharmacological Activity. Indian J Pharm Sci. 1998;60(3):123. http://www.ijpsonline.com/article.asp?issn=0250-

$474 X$; year $=1998$; volume $=60$; issue $=3$; spage $=123$; epage $=127$; aulast $=$ Mandal;type $=0$. Accessed April 25, 2015.

13. Vishwakarma S, Rajani M, Bagul M, Goyal R. A Rapid Method for the Isolation of Swertiamarin from Enicostemma littorale. Pharm Biol. 2004;42(6):400-403. doi:10.1080/13880200490885095.

14. Vaidya H, Rajani M, Sudarsanam V, Padh H, Goyal R. Antihyperlipidaemic activity of swertiamarin, a secoiridoid glycoside in poloxamer-407-induced hyperlipidaemic rats. $J$ Nat $\mathrm{Med}$. 2009;63(4):437-442. doi:10.1007/s11418-009-0350-8

15. Saravanan S, Hairul Islam VI, Prakash Babu N, et al. Swertiamarin attenuates inflammation mediators via modulating NF??B/I ??b and JAK2/STAT3 transcription factors in adjuvant induced arthritis. Eur J Pharm Sci. 2014;56(1):70-86. doi:10.1016/j.ejps.2014.02.005.

16. Vaijanathappa J, Badami S. Antiedematogenic and free radical scavenging activity of swertiamarin isolated from Enicostemma axillare. Planta Med. 2009;75(1):12-17. doi:10.1055/s-00281088333

17. Bhattacharya SK, Reddy PK, Ghosal S, Singh AK, Sharma P V. Chemical constituents of Gentianaceae XIX: CNS-depressant effects of swertiamarin. J Pharm Sci. 1976;65(10):1547-1549.

18. Yamahara J, Kobayashi M, Matsuda H, Aoki S. Anticholinergic action of Swertia japonica and an active constituent. $J$ Ethnopharmacol. 1991;33(1-2):31-35.

http://www.ncbi.nlm.nih.gov/pubmed/1943170. Accessed April 25, 2015.

19. Vaidya H, Rajani M, Sudarsanam V, Padh H, Goyal R. Swertiamarin: A lead from Enicostemma littorale Blume. for antihyperlipidaemic effect. Eur J Pharmacol. 2009;617(1-3):108-112. doi:10.1016/j.ejphar.2009.06.053

20. Kumarasamy Y, Nahar L, Cox PJ, Jaspars M, Sarker SD. Bioactivity of secoiridoid glycosides from Centaurium erythraea. Phytomedicine. doi:10.1078/094471103322004857. $2003 ; 10(4): 344-347$

21. Chiba K, Yamazaki M, Kikuchi M, Kakuda R, Kikuchi M. New physiological function of secoiridoids: neuritogenic activity in $\mathrm{PC} 12 \mathrm{~h}$ cells. J Nat Med. 2011;65(1):186-190. doi:10.1007/s11418-0100449-y.

22. Lam KS. New aspects of natural products in drug discovery. Trends Microbiol. 2007;15(6):279-289.

doi:10.1016/j.tim.2007.04.001.

23. Steven M. Colegate RJM. Bioactive Natural Products: Detection, Isolation, and Structural Determination, Second Edition. CRC Press; 2007

https://books.google.com/books?id=In8kaHnX5gUC\&pgis=1. 


\section{Indo Global Journal of Pharmaceutical Sciences, 2018; 8(1): 1-8}

Accessed July 16, 2015.

24. Kingston DGI. Modern natural products drug discovery and its relevance to biodiversity conservation. J Nat Prod. 2011;74(3):496511. doi:10.1021/np100550t.

25. P, Ayare, Khanvilkar V CN. Flash Chromatography: Area \& Applications | Prachitee Ayare - Academia.edu. PharmaTutor. 2014:89-103.

https://www.academia.edu/6985939/Flash_Chromatography_Area_a nd_Applications. Accessed July 16, 2015.

26. Roge, A.B., Firke, S.N., Kawade, R.M., Sarje, S.K., M. Vadvalkar SM. BRIEF REVIEW ON: FLASH CHROMATOGRAPHY. Int J Pharm Sci Res. 2011;2(8):1930-1937. http://ijpsr.com/wp-content/uploads/2015/02/7-Vol.2-8-IJPSR-281-

Review-7.pdf. Accessed July 16, 2015.

27. Shah GL. Flora of Gujarat State, Volume 1 \& 2. Vallabh Vidyanagar: Sardar Patel University; 1978.

http://books.google.co.in/books/about/Flora_of_Gujarat_State.html?i d=W_sLAAAAMAAJ\&pgis=1. Accessed April 25, 2015.

28. Jaishree V, Badami S, Rupesh Kumar M, Tamizhmani T. Antinociceptive activity of swertiamarin isolated from Enicostemma axillare. Phytomedicine. 2009;16(2-3):227-232.

doi:10.1016/j.phymed.2008.09.010.

29. Magora HB, Rahman MM, Gray AI, Cole MD. Swertiamarin from Enicostemma axillare subsp. axillare (Gentianaceae). Biochem Syst Ecol. 2003;31(5):553-555. doi:10.1016/S0305-1978(02)00200-4. 30. Rana VS. Separation and Identificationof Swertiamarin fromEnicostema axillare Lam.Raynal by Centrifugal PartitionChromatography and NuclearMagnetic ResonanceMassSpectrometry*. J Pharm Sci Emerg Drugs. http://www.scitechnol.com/separation-identification-swertiamarinenicostema-axillare-lam-raynal-centrifugal-partition-

chromatography-nuclear-magnetic-resonancemass-spectrometry-

twei.php\&\&article_id=2477. Accessed July 15, 2015.

31. Patel TP, Soni S, Parikh P, Gosai J, Chruvattil R, Gupta S. Swertiamarin: An active lead from enicostemma littorale regulates hepatic and adipose tissue gene expression by targeting PPAR- $\gamma$ and improves insulin sensitivity in experimental niddm rat model. Evidence-based Complement Altern Med. 2013;2013:1-11. doi:10.1155/2013/358673.

32. Gilbert J, Martin S. Experimental Organic Chemistry: A Miniscale and Microscale Approach. Cengage Learning; 2010. https://books.google.com/books?id=8wIQwCmWz9EC\&pgis $=1$.

Accessed July 15, 2015.

33. Buadavari S. Swertiamarin| The Merck Index. 15TH ed.; 2013. https://www.rsc.org/Merck-

Index/monograph/m10410/swertiamarin?q=unauthorize. Accessed April 25, 2015.

34. Ritter C, Gilliard J. ImpuR: A Collection of Diagnostic Tools Developed in $\mathrm{R}$ in the Context of Peak Impurity Detection in HPLCDAD but Potentially Useful with Other Types of Time-Intensity Matrices. J Stat Softw. 2007;18(9):1-18.

http://www.jstatsoft.org/v18/i09/paper. Accessed July 15, 2015.

35. Tondon N SP. PHYTOCHEMICAL REFERENCE STANDARDS
OF SELECTED INDIAN MEDICINAL PLANTS VOL 1. The Indian Council of Medical Research (ICMR), New Delhi; 2010. http://www.icmr.nic.in/pricepubl/phyto/phyto_vol_1.htm. Accessed April 25, 2015.

36. Stahl M. Peak purity analysis in HPLC and CE using diode-array technology. Agilent Technologies. http://www.chem.agilent.com/Library/applications/59888647EN.pdf. Published 2003. Accessed July 15, 2015.

Indo Global Journal of Pharmaceutical Sciences( ISSN 22491023 ; UGC Journal No.: 44477; CODEN- IGJPAI; NLM ID: 101610675) indexed and abstracted in EMBASE(Elsevier), UGC Journal List, National Library of Medicine (NLM) Catalog, Elsevier( EMBASE), ResearchGate, Publons, CAS (ACS), Index Copernicus, Google Scholar and many more. For further details, visit http://iglobaljournal.com 